\title{
Healing Beliefs and Practices among Subanen and Mansaka
}

\author{
Anabelie V. Valdez and Sanaoray Canapi
}

\begin{abstract}
Healing beliefs and practices among Subanen and Mansaka in Lapuyan Zamboanga Del Sur and Compostela Valley province respectively was examined using qualitative and ethnographic techniques. The data gathered were analyzed using themes namely; factual, traditional and magical. Route and dosage of administration of herbal medicine, as well as the parts of the plant used were also identified. The emic - etic perspectives were used as basis for identifying the scientific basis of the plants used by the Subanen and Mansaka as their herbal remedies. The relative importance and healing practices among Subanen and Mansaka was reported to have some factual evidence.
\end{abstract}

Index Terms-Healing beliefs, emic-etic perspective.

\section{INTRODUCTION}

Ethnoscience is the sum of all the ways that a culture makes its own sense of its milieu, how natives think from the ways in which they perceive relationships among different aspects of their environment [1]. Success within a culture brings many benefits, which are defined by their cultural values. These benefits may include status, monetary rewards, property, control, or admiration. More basic to the culture would be the opportunity to raise a family within a healthy environment [2]. In turn, perceptions and cognitions would help the individual develop the skills that would meet the cultural demands. When individuals engage in successful cultural interactions, they begin to develop beliefs in and about their own capabilities [3].

In the Philippines, indigenous groups have depended on their traditional knowledge for them to survive in an ever changing world up to this present generation. Even before civilization, people groups in their respective areas had long used their indigenous knowledge about their environment and nature in dealing with their daily activities and source of living for survival. This indigenous knowledge is considered as ethnoscience in ethnography and anthropology [4]. Perceptions, knowledge, and classification of the world as reflected in their language of a particular people group are called ethnoscience [5]. Ethnoscience is the sum of all the ways that a culture makes its own sense of its milieu, how natives think from the ways in which they perceive relationships among different aspects of their environment [4].

Manuscript received October 8, 2013; revised December 2, 2013.

Anabelie V. Valdez and Sanaoray Canapi are with the Mindanao State University, Marawi City, Philippines (e-mail: anabelievillavaldez@gmail.com).

\section{METHODOLOGY}

\section{A. Research Design and Methods}

This study is a qualitative research employing ethnographic techniques. Purposive and snowball sampling were used to identify the key informants. Principle of saturation was also used to limit the number of participants. Individual interviews, focus group discussions, community immersions, documentations, observations, and note takings were the primary instruments in data gathering [9].

\section{B. Study Area and Participants of the Study}

The study was undertaken in Lapuyan one of the municipalities in Pagadian City and Mabini Municipality, Compostela Valley province, Mindanao Philippines. The intact indigenous groups were studied in their natural setting. They were studied for duration of two (2) months of intensive field works. The processes of collecting data were flexible that is, emerging from the circumstances encountered in the field, and typically involved a contextual response to the lived realities that arouse unpredictably in the course of the field works.

\section{RESULTS AND DISCUSSIONS}

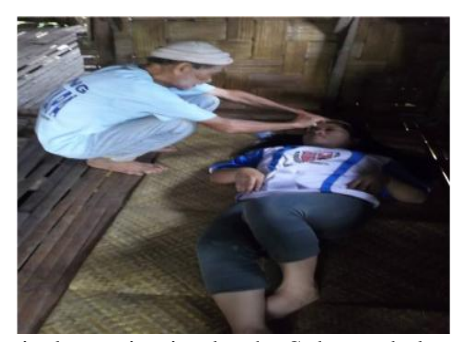

Fig. 1. Magical examination by the Subanen balyan (shaman).

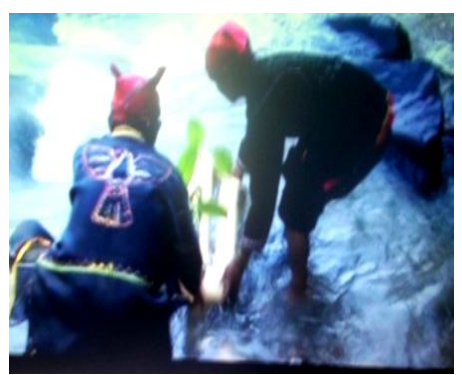

Fig. 2. Ritual conducted by Subanen for driving away the bad spirit

Based on the data gathered from intensive field work, interviews, focus group discussions and community immersions, most of the plants part that is used for herbal medicine by Subanen and Mansaka are leaves, roots, and bark. The route of administration of the medicine is either 
external or internal. Dosage of administration is not fixed and not strictly considered. In analyzing the importance and scientific basis of the therapeutic ability of the plants, I examined the etic perspective of the plants [2]. Upon serious and thorough evaluation and classification of data and information gathered I come up with a three themes in describing the healing beliefs and practices of Subanen and Mansaka. The themes are "magical", "traditional" and "factual". Magical theme is used to describe the healing beliefs and practices of Subanen and Mansaka that employs prayer, and magical intervention that only the shaman knows. Traditional theme is used to describe their healing beliefs and practices that has no scientific basis based on the published scientific standards. Factual theme is used to describe their healing beliefs and practices that conform to the published scientific standard, Fig. 1 and Fig. 2.

Herbal remedies used by Subanen that are ascertained to be factual [6], [7] are the following:

1) The decoction of native mango and rosal root mixture for TB treatment. This practice is validated by some research findings revealing that mango root is a good medicine for tuberculosis, and that not only the roots but the fruits and leaves as well. Rosal on the other hand, has been found to have antiseptic and anti-inflammatory action. The antiseptic component of rosal will destroy or prevent the growth of disease-producing microorganism, while the anti-inflammatory role prevents or reduces inflammation.

2) The use of makahiya roots decoction for birth spacing. Studies showed that the makahiya plant has multiple medicinal applications one of which is the antifertility effect of root decoction which prolongs the estrous cycle and disturb the secretion of gonadotropin hormones. The finding validates the traditional use of makahiya among Subanens as a means of birth control.

3) The use of mahogany seeds for stomach ache problem. This practice is validated by studies revealing that mahogany has an anti-ulcer effect and also work as a good antioxidant. The depurative property of mahogany that can cleanse the body of toxic substances contributes its traditional use to the natives' ethnomedicine since Subanen attest to its efficacy. However, Thimuay Imbing had some words of caution: taking mahogany seed is not advisable for pregnant women because it can cause abortion. This adverse side - effect is proven by studies revealing that mahogany seed has an abortifacient effect.

4) Other plants used by Subanens that have been proven scientifically to have medicinal usefulness include avocado, achuete, guava, mayana, lagundi, papaya, cogon, makopa and lagnob. Avocado, papaya, and guava are an effective treatment for stomach ache due to flatulence, diarrheal, and dysentery effect. Papaya fruit has the ability to clean the stomach; however, Subanen use the seed for treatment due to their belief that bitterness components will cure the stomach ache problem. Makopa is an effective treatment for cough, indigestion, diarrhea and cholera due to its anti-inflammatory and dysenterial effects. Lagundi, mayana, cogon, and lagnob are used for fever treatment due to its febrifuge, analgesic and antimicrobial ability.
5) The external use of achuete leaves by Subanens to expel gas is not clearly elaborated in research findings. Research however, shows that the plant offer itself as an antidote for prussic acid, antimicrobial, purgative and antidiarrheal effect when taken internally or orally.

Herbal plants used by Mansaka that are factual [4], [6]-[8], [10], [12], are the following:

1) Bubuena and ampalaya for cough sakati and malunggay for wound, and handilika or katakataka for boil. Boiling bubuena leaves for 15 minutes and drinking the mixture is an effective cough treatment. However, Mansakas employ hot infusion of bubuena leaves and the juice is extracted and or the leaves are rubbed on the chest and back. For ampalaya, both indigenous and scientific applications are the same.

2) The effectiveness of sakati and malunggay leaves for wound treatment as practiced by the Mansaka people is validated by scientific studies, revealing that sakati has an inhibitory activity and is used by Malaysian as paste applied onto wounds and cuts, while malunggay antiseptic ability will destroy and prevent the growth of infectious agents thereby preventing the wound against infection.

3) The use of kataka-taka leaves for boil treatment conforms with the research findings that kataka-taka leaves extract contain antimicrobial effects.

Herbal plants that are commonly used by both Subanen and Mansaka that have been found to have factual evidences and considered as factual [4], [6]-[8], [10], [12]; include the following:

1) Akapulko is one of the herbal medicines approved by $\mathrm{DOH}$ for skin problem and fungal infection thereby validating the use of this plant as treatment for "ap-ap" (skin discoloration) as practice by Subanen and Manska. Aside from using akapulko leaves, Subanens also use its roots decoction for treating kidney problems. Akapulko has multiple medicinal applications which include diuretic effect that may help cleanse the kidneys of the patient [4].

2) Kalabo, Buyo and Sambong are an effective treatment for cough as practiced by Subanens and Mansakas due to its anti-inflammatory, antibacterial and expectorant ability. Aside from using sambong for cough they also use sambong leaves for fever treatment. Other fever treatments employed by Subanens is the use of banana leaves as cool dressing to lower fever while Mansakas use young banana fruits for LBM and diarrhea. Research findings showed that some medicinal application of banana includes treatment for diarrhea, flatulence, dysentery, indigestion, and for cool dressing of headaches [12].

3) Other herbal treatment used by Subanen and Mansaka for fevers are tawa-tawa and bosikad decoction and or cold infusion (for bosikad). Tawa-tawa and Bosikad are found to have multiple medicinal uses as revealed by scientific studies. The antibacterial and platelet effect of tawa-tawa and the analgesic/hypoglycemic effect of bosikad are the chemical components that will cure fever problem.

4) Using lansones bark for hepatitis as practiced by 
Subanens and for stomach ache as practiced by Mansaka is validated by scientific studies revealing that lansones has antibacterial and antioxidant effects ${ }^{[12]}$

5) Subanens use tuba-tuba for ulcers and toothache while Mansakas use it for hampol of bone dislocation or sprain. Scientific studies showed that tuba-tuba contains hydrogen cyanide, oil and its latex strongly inhibits mosaic virus. These chemical components might be the reason that the Subanens and Mansakas claim therapeutic ability for it.

One of the unique herbal treatments used by Subanen is the mixing of two or more plant species. They usually mixed the scraped bark of pomelo, tuba-tuba, makopa, and star-apple for diarrhea and cholera treatment by drinking the liquid from decoction of the mixture. As established by their experience, such mixture is effective treatment. Its effectiveness will be noticed for about three minutes. Moreover, they also mix native mango roots and rosal roots for tuberculosis treatment. Mixing two or more plant species makes their herbal medicine more effective. The use of traditional and chemical practices by common members of their tribe is based upon the traditional practice of their ancestors and parents [10]. Due to the time - tested efficacy of the herbal plants they use - knowledge handed down from generation to generation they could only wonder why those plants could cure their illnesses. Obviously they do not know the chemical composition of the plants. This naiveté only suggests that although the indigenous people, especially the Subanen and Mansaka, are not in possession of such information - i.e. the chemical composition of plants - they have this learned knowledge inherited from their ancestors is to what valuable uses of certain plants may be put. The advantage of herbal medicine over other medicines is that one can take herbal medicine as a part of their food and there is no need for prescription, whereas commercial artificial medicine requires prescription, otherwise we may be at risk for side-effects [12].

\section{REFERENCES}

[1] A. Barnard. (2009). Ethnoscience. Encyclopedia of Social and Cultural Anthropology. ISBN: 0-203-45803-6. Published: 05-30-2002. (๑2009 Taylor and Francis. Retrieved August 10, 2009. [Online]. Available: http://www.bookrags.com/tandf/ethnoscience-1-tf/-Estados Unidos

[2] V. Evaneshko. (1982). The ethnoscience research technique. Anthropology. Cultural, Classification/methods, Humans, Interview, Psychological. Retrieved August 12, 2009. [Online]. Available: http://www.ncbi.nlm.nih.gov/pubmed/6917637
[3] B. Orlove et al. (2009). Indigenous climate knowledge in southern Uganda: the multiple components of a dynamic regional system. Received: 19 November 2007. Accepted: 29 October 2008. Published online: 23 April 2009@. Retrieved August 5, 2011. [Online]. Available: http://www.jstor.org/pss/258229

[4] T. J. Burgo. (2008). Vansihing stars in Manobo skies. 19:06:00, Retrieved August 11, 2009 from Philippine Daily Inquirer. Ethnoscience - INQUIRER.net, Philippine News for Filipinos. [Online]. http://opinion.inquirer.net/inquireropinion/columns/view/

[5] J. W. Bently. (1999). Handouts for Ethnoscience Course Suphan Buri, Thailand. IRRI: Rice IPM Network. Retrieved August 6, 2011. [Online]. Available: http://www.wikipidia, the free encyclopedia

[6] P. Herbs. (2012). Retrieved. [Online]. Available: http://www.philippineherbs.com/philippineherbinde

[7] S. Godofredo. (2011). Medicinal Plants in the Philippines. [Online]. Available: http://www.stuartxchange.org.html

[8] B. Berlin, Ethnobiological classifications: Principles of categorization of plants and animals in traditional societies. Princeton: Princeton University Press, 1992.

[9] J. W. Creswell, Research Design: Qualitative and Quantitative Approaches, Thousand Oaks, California, SAGE Publications, Inc., 1994.

[10] J. O. Ramos, "Prenatal beliefs and practices among Subanen of Laupyan Zamboanga del Sur," Master's Thesis, 2008.

[11] N. S. Chu, "Effects of Betel nut chewing on the central and autonomic nervous systems," 2001.

[12] H. Therapy. (2011). Alternative Medicine in the Philippines. [Online]. Available: http://www.stuartxchange.org/Herbal.html

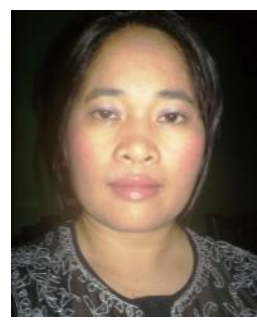

Anabelie V. Valdez born at Aurora Zamboanga del Sur Philippines on March 16, 1975. She finished $\mathrm{Ph} . \mathrm{D}$. science education biology, Ph.D. educational management, Master's in secondary teaching general science and Bachelor of Science secondary education biology in Mindanao State University Marawi City Philippines. She is the chairman in the academic committee at MSU-Balindong Community High School. She is handling biology, physics and general science for this school year. For previous years she is handling chemistry subjects. She is a regular lecturer in the MSU SASE reviews, and lecturer in private review center for the licensure examination for teachers. She wrote 4 researcher related to educational innovations and one research about ethnoscience of indigenous people in Mindanao. Dr. Valdez is a member of the DOST-SEI scholar society and a licensed secondary biology teacher. She presented some papers in the international conference help in the Philippines namely; "World Research Festival", and the $5^{\text {th }}$ SSEASR on healing, religion and beliefs. Recently, she presented her paper in the 2013 IEDRC held at Jakarta Indonesia last July 13-14, 2013.

Sanaoray Canapi is a Muslim and a permanent faculty in Mindanao State University. She is currently taking her Ph.D. Science major in Biology at Mindanao State University as APDP Scholar. 